\title{
Recurrent hemarthrosis after total knee arthroplasty
}

\author{
Alexander Rukavina - Gino M. M. J. Kerkhoffs • \\ Philipp Schneider • Markus S. Kuster
}

Received: 9 September 2009/Accepted: 14 December 2009/Published online: 14 January 2010

(C) The Author(s) 2010. This article is published with open access at Springerlink.com

\begin{abstract}
This report describes a case of spontaneous recurrent hemarthrosis of the knee that presented 4 weeks after total knee arthroplasty. Femoral arteriography showed a false aneurysm of a branch of the inferior lateral geniculate artery. Therapeutic embolization of the arterial branch was performed using three platinum coils with good clinical result and good knee joint function. Hemarthrosis has not recurred since embolization.
\end{abstract}

Keywords Knee - Arthroplasty $\cdot$ Embolization ·

False aneurysm

\section{Introduction}

Vascular complications after total knee arthroplasty are rare and occur in only $0.03-0.2 \%$ [1, 2, 4, 6, 8, 9]. These complications include arterial occlusion, vascular damage, arteriovenous fistulae and aneurysms [1, 2, 4]. If recurrent hemarthrosis becomes manifest after total knee replacement,

A. Rukavina · G. M. M. J. Kerkhoffs · M. S. Kuster Department of Orthopedic Surgery and Traumatology, Kantonsspital, St. Gallen, Switzerland

P. Schneider

Department of Radiology, Kantonsspital, St. Gallen, Switzerland

A. Rukavina

Department of Orthopedic Surgery,

Klinik Orthopaedie am See, Kreuzlingen, Switzerland

G. M. M. J. Kerkhoffs ( $\square)$

Department of Orthopedic Surgery, Academic Medical Center, Amsterdam, The Netherlands

e-mail: g.m.kerkhoffs@amc.nl; ginokerkhoffs@hotmail.com the consequence for the patient is a considerable restriction of movement that jeopardizes the final postoperative result. Rapid, adequate diagnosis and treatment are therefore crucial for a good postoperative outcome. In most cases recurrent hemarthrosis develops from an injury to the popliteal artery and displays the typical clinical characteristics of pulsating tumor, audible arterial murmur, and differences in the systolic blood pressure of the lower extremity. We present a rare case of a recurrent hemarthrosis after total knee arthroplasty.

\section{Case report}

A 72-year-old woman who suffered from medial osteoarthritis of her right knee joint got joint replacement surgery. A cemented total knee prosthesis (type LCS, Johnson \& Johnson, New Brunswick, New Jersey, USA) was placed through a medial arthrotomy. During the procedure a tourniquet was applied at $300 \mathrm{~mm} \mathrm{Hg}$. The surgical procedure was uneventful as was the initial postoperative course. The patient was discharged 1 week postoperatively with a slender, stable knee and stable wound healing; knee flexion was $100^{\circ}$ with full extension.

One month postoperatively the patient presented to the casualty department at our hospital. She reported that the knee joint had suddenly swollen after rising from a chair. Aspiration of the joint showed a $40 \mathrm{ml}$ hemarthrosis. The knee motion was significantly reduced. The foot and popliteal pulses were well palpable and no pulsating swelling was felt in the popliteal fossa. The bacteriological investigation of the hemarthrosis was sterile and the values for chemical laboratory parameters were all normal. The radiological assessment showed proper axial alignment without signs of loosening. On the basis of these findings 
conservative treatment with analgetics, cool packs and physiotherapy were applied.

She represented to the casualty department with recurrent hemarthrosis within 10 days after the first presentation. Consequently an arthroscopy was performed to confirm the tentative diagnosis of recurrent bleeding from Hoffa impingement. Arthroscopy identified two possible sources of bleeding in Hoffa's fat pad and these were coagulated. One week after arthroscopy, hemarthrosis reoccurred for the third time. This time a femoral arteriography under local anesthesia was performed. A false aneurysm of a branch of the inferior lateral geniculate artery was discovered (Figs. 1 and 2) and successfully embolized in the same session with a total of three platinum-coated coils (Vort X-18 diameter $3 \mathrm{~mm}$, length $23 \mathrm{~mm}$; Boston Scientific Switzerland AG). The follow-up 3 months after embolization showed that the patient was free from symptoms and had regained full motion $\left(110^{\circ}-0\right.$ $0)$. Two years postoperatively there were no further instances of knee swelling and the range of motion remained $110^{\circ}-0-0$.

\section{Discussion}

The importance of the current report lies in the recognition of an arteriography as a possible tool to identify the cause of the hemarthrosis and subsequently in the acceptation of a treatment algorithm for unexplained hemarthrosis after total knee arthroplasty.

Recurrent hemarthrosis after total knee arthroplasty occurs in less than $1 \%$, but if it is does occur it seriously jeopardizes the postoperative outcome $[3,4,6]$. Rapid diagnosis and adequate treatment are crucial to avoid permanent limitations of movement.

There are various causes of recurrent hemarthrosis $[2,3]$. Intraoperative injury to the vessels may go unnoticed.

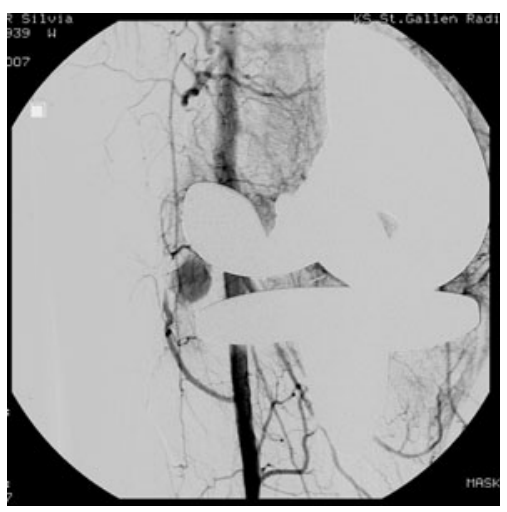

Fig. 1 Non-selective arteriography showing false aneurysm of the inferior lateral geniculate artery. The vascular system in the field of investigation is otherwise normal

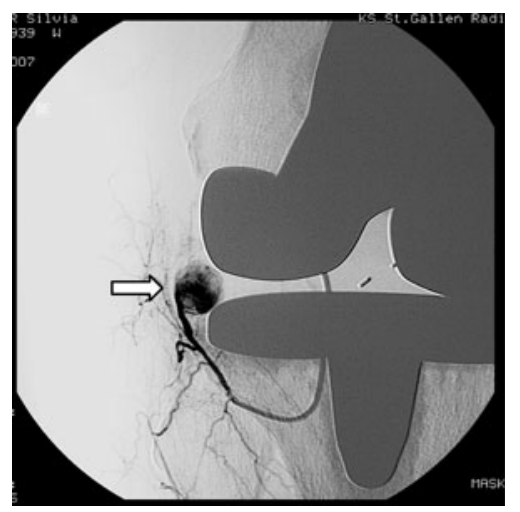

Fig. 2 Selective arteriography of the inferior lateral artery shows a powerful jet (white arrow) from the lateral branch into the false aneurysm

Another frequent cause of recurrent hemorrhaging is the entrapment of synovial tissue or Hoffa's fat pad-Impingement between the prothetic joint components $[3,7]$. This produces the classical signs of ischemia and symptoms may be interpreted as deep crural thrombosis [5].

Unexplained recurrent hemarthrosis after total knee arthroplasty should be treated in stages: In every case needle aspiration for relief of pain and stiffness should be performed at first, also to confirm the diagnosis. Aspiration of the effusion followed by conservative methods (cooling, elevation, and rest) will prevent in most cases further hemorrhage [10]. If conservative treatment is not successful, as next step a femoral arteriography should be considered to obtain further clarification. Femoral arteriography is a very profitable investigation in the search for the source of bleeding and immediate embolization (arteriovenous fistulae, aneurysms) [10]. Embolization of the source of bleeding via the in situ catheter is a straightforward and effective method. In our presented case, the third hemarthros could probably have been prevented when we would have taken this step before the arthroscopic evaluation. The embolization has significant advantages compared to an arthroscopic or open surgical revision: local anesthesia only, minimal risk of infection and subsequent rapid mobilization of the knee, which is essential for the clinical outcome. If embolization is unsuccessful, arthroscopy is the next step, because it is both a diagnostic and a therapeutic instrument. Entrapped tissue and any sources of bleeding can then be localized and treated, using a vaper. If this approach is unsuccessful an open synovectomy is indicated; thus only when the cause of recurrent hemarthrosis remains unclear after the previously mentioned steps have been conducted.

Conflict of interest statement The authors report no conflict of interest. 
Open Access This article is distributed under the terms of the Creative Commons Attribution Noncommercial License which permits any noncommercial use, distribution, and reproduction in any medium, provided the original author(s) and source are credited.

\section{References}

1. Dennis DA, Neumann RD, Toma P, Rosenberg G, Mallory TH (1987) Arteriovenous fistula with false aneurysm of the inferior medial geniculate artery. J Clin Orthop 222:255-260

2. Hozack WJ, Cole PA, Gardner R, Corces A (1990) Popliteal aneurysm after total knee arthroplasty: case reports and review of the literature. J Arthroplasty 5:301-305

3. Kindsfater K, Scott R (1995) Recurrent haemarthrosis after total knee arthroplasty. The Journal of Arthroplasty 10(Suppl.:):S52S55

4. Langkamer VG (2001) Local vascular complication after knee replacement: a review with illustrative case reports. Knee 10(Suppl. 8):259-264
5. Maheshwari R, Kelly SP, Langkamer VG, Loveday E (2004) Spontaneous recurrent haemarthrosis following unicompartimental knee arthroplasty and its successful treatment by coil embolisation. The Knee 11(5):413-415

6. O'Connor JV, Stocks G, Grabtree JD Jr, Galasso P, Wallsh E (1998) Popliteal pseudoaneurysm following total knee arthroplasty. J Arthroplasty 13:830-832

7. Oishi CS, Elliott ML, Colwell CW Jr (1995) Recurrent haemarthrosis following a total knee arthroplasty. J Arthroplasty 10:S56-S58

8. de Raet J, Verhaven E, Kemnitz S (2007) Late spontaneous haemarthrosis: an unusual complication following an unicompartmental knee arthroplasty. Knee Surg Sports Traumatol Arthrose 15:763-765

9. Sharma H, Singh GK, Cavanagh SP, Kay D (2006) Pseudoaneurysm of the inferior medial geniculate artery following primary total knee arthroplasty: delayed presentation with recurrent haemorrhagic episodes. Knee Surg Sports Traumatol Arthrosc 14:153-155

10. Varatharaj M, Dawson C, Ciu Q, Mihalko WM, Saleh KJ, Brown T (2006) Popliteal artery pseudoaneurysm following total knee Arthroplasty: a case report. Eur J Orthop Surg Traumatol 17:313315 